\title{
Concentration of Opioid-Related Industry Payments in Opioid Crisis Areas
}

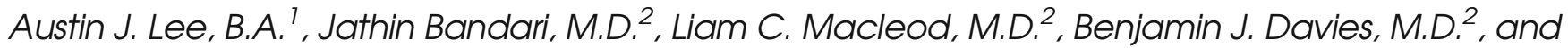 \\ Bruce L. Jacobs, M.D., M.P.H. ${ }^{2}$ \\ 'University of Pittsburgh School of Medicine, Pittsburgh, PA, USA; ${ }^{2}$ Department of Urology, University of Pittsburgh Medical Center, Pittsburgh, PA, \\ USA.
}

$\mathrm{J}$ Gen Intern Med 34(2):187-9

DOI: $10.1007 / \mathrm{s} 11606-018-4700-7$

(c) Society of General Internal Medicine 2018

\section{INTRODUCTION}

The misuse of opioids has led to dramatic increases in opioid-related mortality with opioid-related deaths increasing by $345 \%$ from 2001 to 2016 in the USA. ${ }^{1,2}$ The marketing of opioids by the pharmaceutical industry to providers is well documented, with 1 in 12 US physicians receiving opioid-related industry payments. ${ }^{3}$ However, it is unclear how or even if pharmaceutical industry payments are related to opioid-related deaths, or if disparities exist in marketing efforts for at-risk populations. We examined if opioid-related industry payments to healthcare providers were associated with opioidrelated deaths by US county in 2016 .

\section{METHODS}

We used the Centers for Medicare \& Medicaid Services (CMS) Open Payments General Payment 2016 database to examine industry (non-research, non-ownership related) payments given by county to providers in association with opioid drugs, as listed on the CMS Opioid Drug List. ${ }^{4}$ We obtained opioid-related deaths in 2016 by county from the Centers for Disease Control and Prevention WONDER Multiple Cause of Death database by classifying underlying cause of death related to poisoning (ICD-10 codes X40-X44, X60-64, X85, and Y10-Y14) and multiple cause of death codes related to opioids (ICD-10 codes T40.0-T40.4 and T40.6). ${ }^{5}$

To account for variation in county size, we adjusted opioid-related deaths and opioid-related open payments by county population in 2016 as provided by the WONDER database. We used the Spearman rank correlation to analyze the association of the per capita opioidrelated open payments and per capita opioid-related deaths by county. Geographic data of payments and deaths were mapped using geographic information system technology (ArcGIS; Redlands, CA). ${ }^{6}$ This study

Published online November 6, 2018 utilized public databases and therefore was exempt from Institutional Review Board approval.

\section{RESULTS}

In 2016, there were 42,249 opioid-related deaths in the country with an overall rate of 13.1 deaths per 100,000 population. The top three counties in per capita opioid-related deaths were Harrison County in Kentucky and Cabell County and Wayne County in West Virginia (118, 91, and 84 deaths per 100,000 population, respectively). The pharmaceutical industry gave out 172,147 opioid-related payments totaling $\$ 9,861,414$ to 31,532 unique providers. Payment categories consisted of speaking fees $(\$ 5,101,067 ; n=3553)$, meals $(\$ 2,674,994$; $n=166,143)$, consulting fees $(\$ 1,456,925 ; n=525)$, travel $(\$ 583,891 ; n=1501)$, honoraria $(\$ 46,010 ; n=48)$, and education $(\$ 3927 ; n=377)$. The payments were made by 11 different pharmaceutical companies, with 4 paying more than $\$ 1$

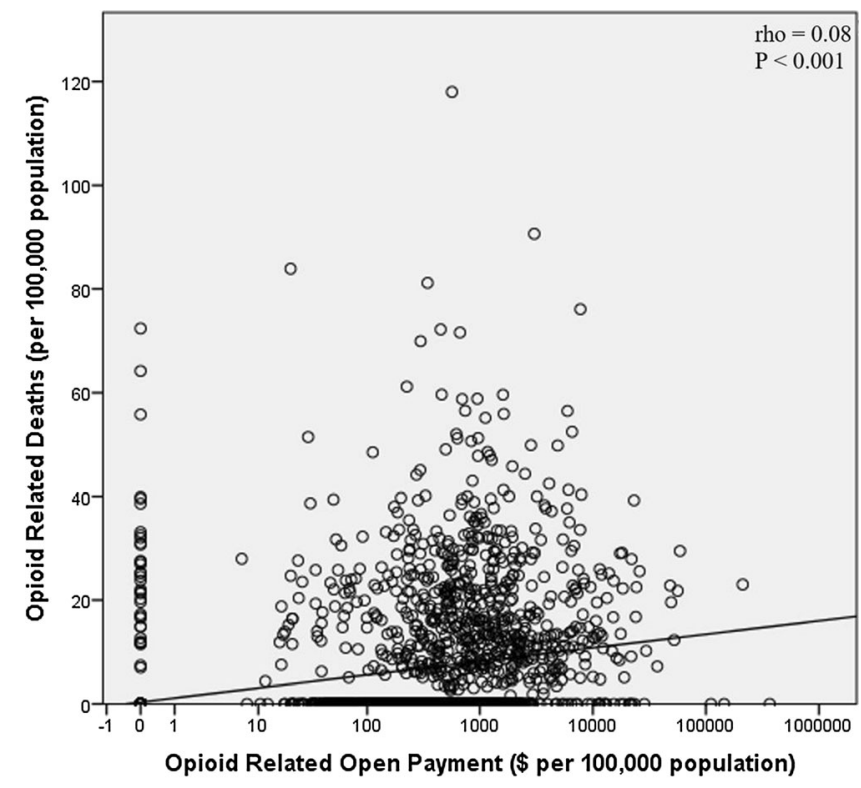

Figure 1 Relationship between opioid-related open payment amount and opioid-related deaths by US county in 2016. Both are calculated per 100,000 population in the given county. Each point represents a separate US county. There was a weak, statistically significant relationship between opioid-related open payment amount and opioid-related deaths. $P$ values were generated using the Spearman rank correlation. 
million: Depomed, Inc. $(\$ 2,738,320)$, Purdue Pharma L.P. $(\$ 2,579,917)$, INSYS Therapeutics Inc. $(\$ 2,393,125)$, and Pfizer Inc. $(\$ 1,105,197)$. County opioid-related deaths had an average of 4.5 deaths per 100,000 population (standard deviation [SD], 10.5) and opioid-related industry payments had an average of $\$ 1137$ (SD 8833) per 100,000 population.
There was a statistically significant association between per capita opioid-related industry payments and per capita opioidrelated deaths by county (rho $=0.08, P<0.001$ ) (Fig. 1). An increase in $\$ 10,000$ opioid-related industry payments per 100,000 population was associated with an increase in 0.89 opioid-related deaths per 100,000 population. The distribution
A. Opioid-related deaths by US county in 2016.

\section{Opioid Related Deaths per 100,000 population}

$>30$

25-30

20-25

$\square$ 15-19.9

10-14.9

$\square$ 5-9.9

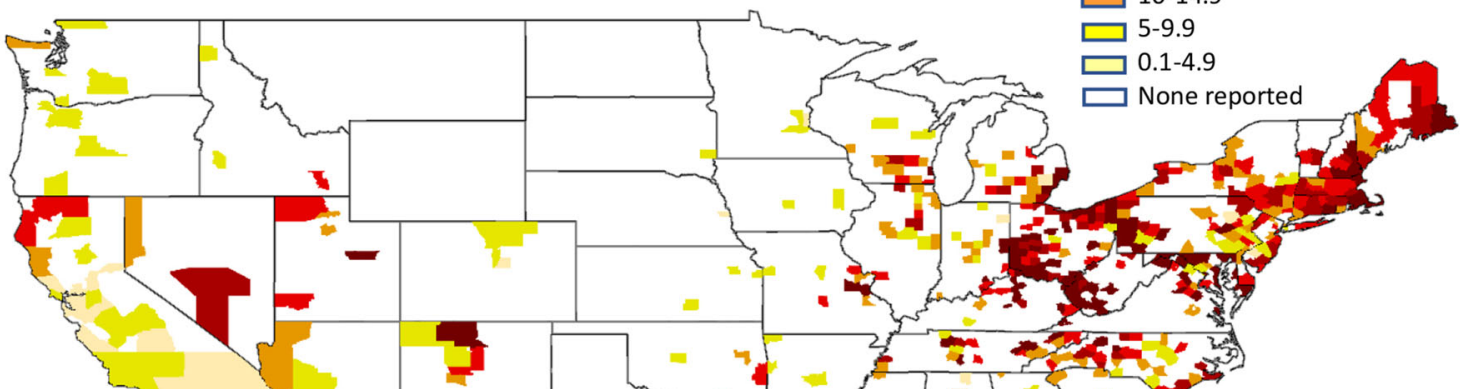

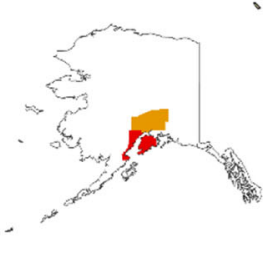

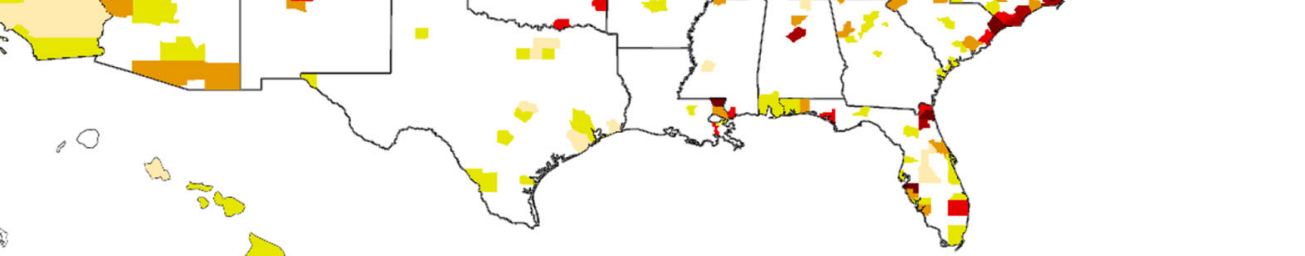

B. Opioid-related industry payments by US county in 2016.

Opioid Related Industry Payments per 100,000 population Top Quartile (\$366 471 - \$1170)

$\square 3^{\text {rd }}$ Quartile (\$1170 - \$498)

$\square 2^{\text {nd }}$ Quartile $(\$ 201-498)$

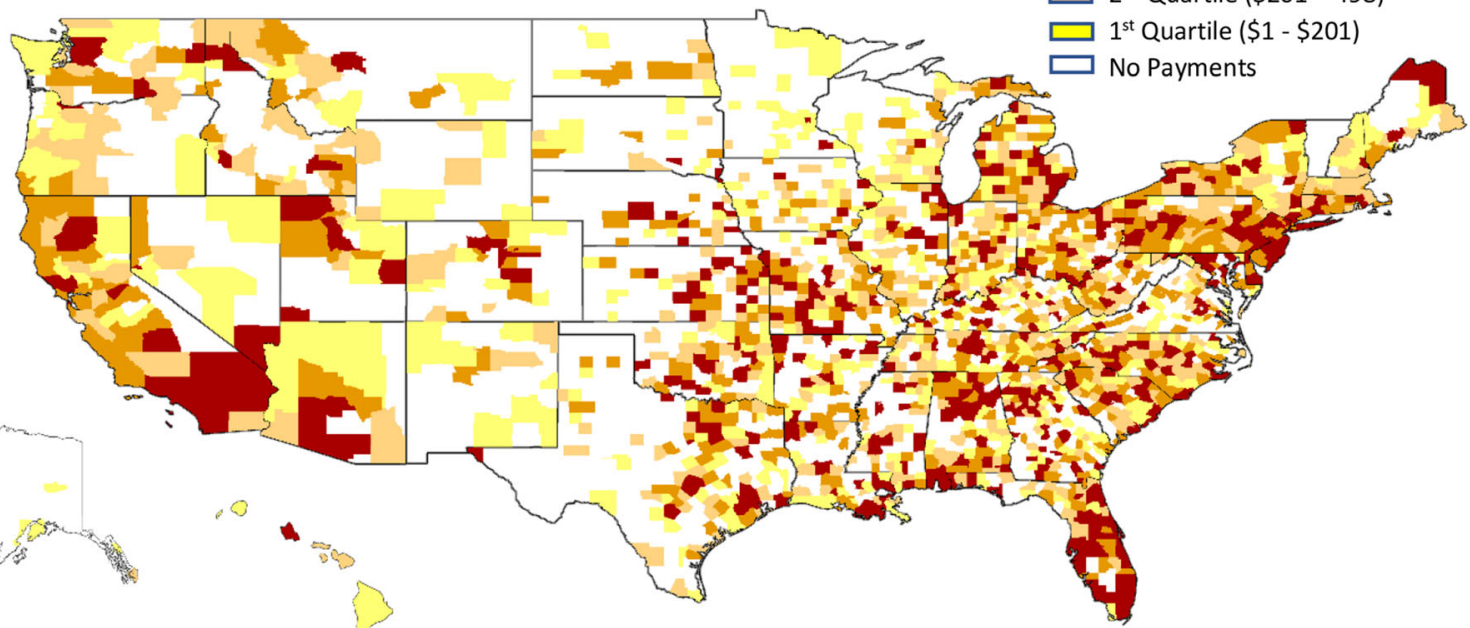

Figure 2 Mapping of opioid-related deaths and opioid-related industry payments by US county in 2016. a Opioid-related deaths per 100,000 by US county in 2016. b Opioid-related industry payments per capita by US county in 2016. Counties are categorized by quartiles of regions that received opioid-related industry payments. 
of opioid-related deaths and opioid-related industry payments is mapped in Figure 2.

\section{DISCUSSION}

Our study demonstrated that US counties that receive more opioid-related industry payments had more opioidrelated deaths. To our knowledge, this is the first study investigating industry payments and mortality data. While it is tempting to conclude that these payments caused more indiscriminate opioid prescribing and subsequent overdoses, there are also alternate explanations. The causal arrow may point in the other direction-companies may direct payments to areas where there are higher rates of opioid prescribing. There may be unresolved confounding or ecologic effects. Nonetheless, the results are very concerning and call for further investigation. In the midst of a nationwide opioid crisis, it is imperative to rigorously consider the risks and benefits of industry payments on opioid abuse in at-risk populations.
Corresponding Author: Austin J. Lee, B.A.; University of Pittsburgh School of Medicine, Pittsburgh, PA, USA (e-mail: Ajl97@pitt.edu).

\section{Compliance with Ethical Standards:}

Conflict of Interest: The authors declare that they do not have a conflict of interest.

\section{REFERENCES}

1. Rudd RA, et al. Increases in drug and opioid overdose deaths-United States, 2000-2014. Am J Transplant, 2016. 16(4): p. 1323-1327.

2. Gomes T, et al. The Burden of Opioid-Related Mortality in the United States. JAMA Network Open, 2018. 1(2): p. e180217-e180217.

3. Hadland SE, Krieger MS, Marshall BD. Industry payments to physicians for opioid products, 2013-2015. Am J Public Health, 2017. 107(9): p. 1493-1495.

4. Centers for Medicare and Medicaid Services. Open payments dataset downloads. Available from: https://openpaymentsdata.cms.gov/dataset/ General-Payment-Data-Detailed-Dataset-2016-Reporti/sc9t-h3c3. Accessed 4 Aug 2018

5. Hedegaard H, Warner M, Minino AM. Drug Overdose Deaths in the United States, 1999-2016, in NCHS Data Brief, no 294. 2017, National Center for Health Statistics: Hyattsville.

6. Environmental Systems Research Institute, ArcGIS (2017) Redlands, CA. 